\title{
PENINGKATAN PENGUASAAN KONSEP FISIKA MENGGUNAKAN LABORATORIUM VIRTUAL PHET MATERI TEORI KINETIK GAS
}

\author{
Adytia Permana Putra1, Chaerul Rochman', dan Winda Setya ${ }^{1}$ \\ ${ }^{1}$ Program Studi Pendidikan Fisika, Fakultas Tarbiyah dan Keguruan, UIN Sunan Gunung Djari \\ Bandung, Indonesia \\ E-mail: adytiaapp@gmail.com
}

\begin{abstract}
ABSTRAK
Pembelajaran fisika sering dikatakan sulit oleh peserta didik karena rumit dan membosankan sehingga peserta didik merasa kurang menguasai konsep dalam pembelajaran fisika. Dibutuhkan media pembelajaran laboratorium virtual PhET strategi yang mampu memberikan dorongan kepada peserta didik untuk mengoptimalkan kegiatan pembelajaran. Tujuan penelitian ini untuk mengetahui tingkat keterlaksanaan penggunaan laboratorium virtual PhET dalam meningkatkan penguasaan konsep peserta didik materi teori kinetik gas. Sampel penelitian seluruh peserta didik kelas XI MIPA 1 SMA Al-Hidayah Ciparay berjumlah 33 orang. Metode penelitian yang dilakukan adalah metode pre experimental dengan penggunaan desain one group pretest-posttest. Instrumen yang digunakan lembar Student Activity Sheet (SAS) hasil jawaban peserta didik berbasis Authentic Assessment Based on Teaching Learning Trajectory (AABTLT) dan tes penguasaan konsep peserta didik. Hasil penelitian menunjukan bahwa (1) persentase rata-rata keterlaksanaan proses kegiatan pembelajaran penggunaan laboratorium virtual $\mathrm{PhET}$ yaitu $72 \%$ dengan kategori efektif, (2) peningkatan penguasaan konsep peserta didik diperoleh melalui nilai $\mathrm{N}$-Gain sebesar 0,635 mengalami peningkatan yang sedang.
\end{abstract}

Kata kunci: Laboratorium virtual PhET, SAS, AABTLT, Penguasaan Konsep.

\begin{abstract}
Laboratory learning media PhET strategy is able to encourage students to optimize learning activities. The purpose of this study is to determine the feasibility of using a virtual PhET laboratory to improve students' mastery of the concept of kinetic gas theory. The research sample of all students of class XI MIPA 1 of Al-Hidayah Senior High School amounted to 33 people. The research method used was pre experimental method with the use of one group pretest-posttest design. The instruments used were Student Activity Sheet (SAS) answer sheets basedon Authentic Assessment Based on Teaching Learning Trajectory (AABTLT) based students and students' concept mastery tests. The results of the study (1) the percentage of the implementation of the learning process using the PhET virtual laboratory that is $72 \%$ effective category. (2) students' mastery of concepts obtained N-Gain value of 0.635 experienced a moderate increase.
\end{abstract}

Keywords: Laboratory virtual PhET, SAS, AABTLT, Mastery of concept

DOI: $\underline{\text { http://dx.doi.org/10.15575/jotalp.v5i2.7991 }}$

Received: 11 Maret 2020 ; Accepted: 09 Juli 2020 ; Published: 31 Agustus 2020 


\section{PENDAHULUAN}

Kemajuan teknologi dan informasi di Indonesia saat ini mengalami peningkatan yang cukup pesat. Seiring meningkatnya teknologi dan informasi, para ahli pendidikan sudah mulai menggunakan media pembelajaran berbasis komputer contohnya video interaktif, media power point, buku elektronik (ebook), macro flash, dan penggunaan laboratorium virtual (Sumargo, 2014:120). Penggunaan media pembelajaran yang sesuai akan membuat pembelajaran lebih menarik, membuat peserta didik aktif, dan meningkatkan minat untuk mau belajar. Salah satu media pembelajaran yang akan digunakan dalam penelitian adalah laboratorium virtual PhET. Pemilihan penggunaan laboratorium virtual PhET sebagai media pembelajaran karena simulasi ini dirancang untuk memudahkan para pengajar untuk memandu peserta didik mengembangkan penguasaan mereka terhadap konsep fisika. Simulasi PhET yang digunakan terdiri dari objekobjek yang tidak terlihat oleh mata di dunia nyata contohnya molekul-molekul kecil, elektron, medan listrik dan foton (Sunni, 2014:104). Sehingga pembelajaran laboratorium virtual PhET menjadi lebih efisien dan terlaksana lebih cepat dibandingkan pembelajaran dengan laboratorium nyata.

Hasil wawancara dengan salah satu guru fisika di SMA Al-Hidayah Ciparay bahwa umumnya pembelajaran masih berorientasi pada pemaparan guru, dan belum terdapatnya ruang laboratorium untuk melakukan percobaan fisika sehingga peserta didik merasa bosan mengikuti proses pembelajaran yang sering dilakukan di kelas. Hal ini yang membuat peneliti tertarik untuk menggunakan laboratorium virtual PhET sebagai media pembelajaran. Manfaat penggunaan simulasi PhET yang dilakukan agar guru dapat menjelaskan suatu konsep abstrak kepada peserta didik yang tidak mungkin dijelaskan secara lisan salah satunya yaitu materi teori kinetik gas.

Teori kinetik gas adalah materi yang berkaitan dengan hukum gas ideal suatu materi yang abstrak terdiri dari molekul-molekul kecil yang saling bertumbukan. Jika dijelaskan secara verbal, maka peserta didik akan mengalami kesulitan dalam memahami materi teori kinetik gas. Media pembalajaran laboratorium virtual PhET solusi yang efektif untuk meningkatkan sajian secara visual kepada peserta didik, agar materi yang diajarkan secara abstak atau sulit akan mudah dipahami. Hal ini sesuai pendapat yang dilakukan oleh Bagus Syaifulloh (2014:174) pembelajaran fisika materi teori kinetik gas menggunakana laboratorim virtual PhET dapat membuat peserta didik aktif dan antusias dalam pembelejaran.

Media pembelajaran berbasis media komputer dalam laboratorium virtual PhET sebagai strategi pembelajaran dalam menguasai konsep fisika. Simulasi PhET yang dilakukan dapat dijadikan suatu pendekatan pelajaran yang membutuhkan keterlibatan dan interaksi dengan peserta didik. Mendidik peserta didik agar memiliki pola berpikir konstruktivisme yaitu mengharuskan peserta didik dapat menggabungkan pengetahuan awal yang sudah dimiliki dengan penggunaan simulasi PhET yang dijalankan membuat pembelajaran lebih menarik karena peserta didik dapat belajar sekaligus bermain pada simulasi tersebut, dan memvisualisasikan penguasaan konsep fisika yang dimiliki peserta didik (Permata, 2013:2).

Subali (2010:91) dalam menguasai konsep suatu pembelajaran, peserta didik diharapkan dapat menyelesaikan berbagai masalah fisika sesuai dengan penguasaan konsep masing-masing peserta didik berlandaskan pada pengetahuan yang dimiliki. Proses pembelajaran ini diharapkan semakin bermakna bagi peserta didik, sehingga apa yang sudah didapatkan tidak mudah lupa. Penguasaan konsep dalam pelajaran fisika merupakan kemampuan peserta didik 
dalam memahami konsep-konsep fisika setelah proses pembelajaran. Penguasaan konsep dapat diartikan sebagai kemampuan peserta didik dalam memahami makna secara ilmiah atau teori maupun penerapannya dalam kehidupan seharihari, sehingga standar kompetensi lulusan pembelajaran fisika dan tercapai terutama dalam menguasai konsep dan materi yang diajarkan (Dahar,2003:4).

Hasil observasi di SMA Al-Hidayah diperoleh bahwa Penilaian Akhir Tahun (PAT) rata-rata nilai PAT yaitu 48, nilai tertinggi 60 , dan nilai terendah 25. Ketercapaian pembelajaran penguasaan konsep fisika masih tergolong rendah, saat mencari informasi bukti autentik mengenai penguasaan konsep peserta didik selama keterlaksanaan proses pembelajaran sulit bagi peneliti untuk mengetahui informasi secara keseluruhan. Dibutuhkan suatu media pembelajaran pendekatan atau strategi yang dirancang untuk memberikan dorongan kepada peserta didik agar berpikir selama proses pembelajaran agar penguasaan konsep fisika peserta didik merata. Pendekatan pembelajaran yang berpusat atau berorientasi pada peserta didik secara umum dapat meningkatan penguasaan konsep dan minat dalam belajar. Hasil angket yang tersaji pada saat studi pendahuluan peserta didik tertarik untuk menggunakan media pembelajaran laboratorium virtual PhET di tunjukan pada Tabel 1.

Tabel 1. Respon peserta didik penggunaan laboratorium virtual PhET

\begin{tabular}{lc}
$\begin{array}{c}\text { Respon } \\
\text { peserta didik }\end{array}$ & $\begin{array}{c}\text { Persentase } \\
\text { rata-rata (\%) }\end{array}$ \\
\hline Sangat penting & $21 \%$ \\
\hline Penting & $67 \%$ \\
\hline Sangat tidak penting & $9 \%$ \\
\hline Tidak penting & $3 \%$ \\
\hline
\end{tabular}

Tabel 1 menunjukan bahwa respon peserta didik terhadap penggunaan media pembelajaran laboratorium virtual PhET menyatakan bahwa $21 \%$ peserta didik sangat penting, $67 \%$ penting, 9\% tidak penting, dan $3 \%$ sangat tidak penting.
Hasil angket secara keseluruhan diperoleh bahwa peserta didik tertarik untuk menggunakan simulasi PhET. Jika media pembelajaran laboratorium virtual PhET digunakan, maka akan terjadi dampak positif yang siginifikan terhadap penguasaan konsep peserta didik dibandingkan pembelajaran yang sering menggunakan pembelajaran konvensional (Sunni, 2014:107). Menurut Perkins dkk (2012:298) penggunaan media pembelajaran simulasi PhET menarik dan efektif untuk peserta didik pada Sekolah Menengah Atas (SMA).

Berdasarkan uraian yang telah dipaparkan, maka peneliti tertarik untuk melakukan penelitian tentang penggunaan laboratorim virtual PhET sebagai media pembelajaran untuk meningkatkan penguasaaan konsep peserta didik pada materi teori kinetik gas. Fokus tujuan penelitian ini dilakukan untuk mengetahui efektifitas keterlaksanaan penggunaan media pembelajaran simulasi PhET dalam meningkatkan penguasaan konsep peserta didik pada materi teori kinetik gas.

\section{METODE PENELITIAN}

Penelitian ini menggunakan pendekatan kuantitatif dan metode penelitian preexperimental dengan desain yang digunakan one group pretest-postest untuk mengukur penguasaan konsep peserta didik sebelum dan setelah penggunaan laboratorium virtual PhET. One Groups Pretest-Postest adalah desain penelitian terdapat pretest sebelum diberi perlakuan dan posttest setelah diberi perlakuan (Sugiyono, 2001:64). Desain penelitian yang digunakan tersaji pada Tabel 2.

Tabel 2. Desain penelitian one-group pretest -posttest design

\begin{tabular}{ccc}
\hline Pretest & Perlakuan & Posttest \\
\hline $\mathrm{O}_{1}$ & $\mathrm{X}$ & $\mathrm{O}_{2}$ \\
\hline
\end{tabular}


Keterangan:

$\mathrm{O}_{1}=$ tes yang dilakukan sebelum diberi perlakuan (pretest),

$\mathrm{X}=$ tes yang diberikan (treatment) menerapkan experimen laboratorium virtual PhET dengan tambahan pertanyaan berupa quiz selama kegiatan pembelajaran berlangsung, dan

$\mathrm{O}_{2}=$ tes yang dilakukan setelah diberi perlakuan (posttest).

Tempat penelitian dilakukan di SMA Al-Hidayah Ciparay Kabupaten Bandung di kelas XI MIPA 1 dengan jumlah peserta didik 33 orang, diberikan pretest pada pertemuan pertama, diberikan perlakuan dengan penggunaan laboratorium virtual PhET materi teori kinetik gas yaitu hukum Boyle pada pertemuan kedua, hukum Gay Lussac pertemuan ketiga, hukum Charles pertemuan ke empat, dan diberikan posttest pada pertemuan ke lima. Hasil dari pretest dan posttest peserta didik digunakan untuk menghitung normalizaed gain ( $N$-Gain) agar mengetahui tingkat penguasaan konsep peserta didik materi teori kinetik gas penggunaan laboratorium virtual PhET. Apabila nilai $N$-Gain sudah didapatkan, maka nilainya akan diinterpretasikan ke dalam Tabel 3.

Tabel 3. Kriteria tingkat efektifitas pembelajaran (Hake, R, 1999:1)

\begin{tabular}{cc}
\hline Interval & Kriteria \\
\hline $\mathrm{g}>0,7$ & Tinggi \\
\hline $0,3 \leq \mathrm{g} \leq 0,7$ & Sedang \\
\hline $\mathrm{g}<0,3$ & Rendah \\
\hline
\end{tabular}

Selama proses kegiatan pembelajaran berlangsung penelitian ini mengukur tingkat keterlaksanaan penggunaan laboratorium virtual PhET dalam pembelajaran fisika. Tingkat keterlaksanaan pembelajaran fisika dilakukan untuk mendapatkan profil peserta didik atas ketercapaian pembelajaran fisika dengan penilaian menggunakan Authentic Assessment Based on Teaching Learning Trajectory (AABTLT) with Student Activity Sheet (SAS) materi teori kinetik gas. AABTLT with SAS merupakan penilaian autentik peserta didik berdasarkan urutan mengajar guru dan belajar peserta didik. Penilaian autentik digunakan berupa portofolio yang mampu mengungkapkan kemampuan keseluruhan belajar peserta didik melalui kegiatan pendahuluan, kegiatan inti dan kegiatan penutup.

Data yang diperoleh dari keterlaksanaan pembelajaran fisika dengan teknik penilaian AABTLT with SAS berupa quiz atau jawaban peserta didik pada portofolio sesuai urutan pertanyaan atau quiz yang diajukan guru selama proses pembelajaran berlangsung. Prosedur Keterlaksanaan pembelajaran yang dilakukan peserta didik setiap pertemuannya dimbing langsung oleh guru dalam melakukan percobaan penggunaan laboratorium virtual PhET. Di selasela percobaan dan diskusi, guru memberikan quiz yang wajib dijawab oleh peserta didik pada lembar (SAS) yang sudah disiapkan dengan waktu yang bervariasi. Peserta didik menjawab pertanyaan quiz yang diberikan guru kemudian diberikan skor yang telah ditetapkan sebelumnya memiliki nilai rentang 0-4 tersaji pada Tabel 4.

Tabel 4. Rubrik penilaian AABTLT with SAS (Rochman dkk., 2018:3)

\begin{tabular}{cl}
\hline Skor & \multicolumn{1}{c}{ Kriteria } \\
\hline 0. & jika responden tidak memberikan jawaban, \\
\hline 1. & $\begin{array}{l}\text { jika responden memberikan jawaban yang } \\
\text { salah, }\end{array}$ \\
\hline 2. & $\begin{array}{l}\text { jika jawaban yang diberikan benar namun } \\
\text { kurang lengkap, }\end{array}$ \\
\hline 3. & $\begin{array}{l}\text { jika jawaban yang diberikan benar dan } \\
\text { lengkap, tetapi belum sempurna sesuai } \\
\text { dengan harapan, dan }\end{array}$ \\
\hline 4. & jika jawaban sempurna/sesuai \\
\hline
\end{tabular}

Lembar hasil SAS peserta didik diberikan skor setiap tahapan quiz saat proses kegiatan pembelajaran materi teori kinetik gas dinyatakan dengan persentase menggunakan persamaan.

$$
\text { Persentase }=\frac{\text { Skor diperoleh }}{\text { Skor maksimum }} \times 100 \%
$$


Hasil SAS yang sudah diberikan persentase akan dianalisis tersaji pada Tabel 5.

Tabel 5. Kriteria capaian pembelajaran (Rochman dkk, 2018:4)

\begin{tabular}{cc}
\hline Persentase & Interpretasi \\
\hline$<55$ & Tidak efektif \\
\hline $55-70$ & Kurang efektif \\
\hline $71-80$ & Efektif \\
\hline$>85$ & Sangat efektif \\
\hline
\end{tabular}

\section{HASIL DAN PEMBAHASAN}

Pengolahan data yang telah dilakukan diperoleh beberapa hasil penelitian penggunaan simulasi PhET yaitu profil persentase rata-rata keterlaksanaan kegiatan pembelajaran setiap pertemuan, profil keterlaksanaan setiap tahapan pembelajaran SAVI, profil penguasaan konsep peserta didik materi teori kinetik gas, dan profil rata-rata setiap quiz. Berikut ini akan dijelaskan hasil penelitian yang telah dilakukan

\section{Profil Persentase Rata-Rata Keterlaksanaan Kegiatan Pembelajaran Setiap Pertemuan}

Profil persentase rata-rata keterlaksanaan kegiatan pembelajaran setiap pertemuan penggunaan media pembelajaran laboratorium virtual PhET tersaji pada Gambar 1.

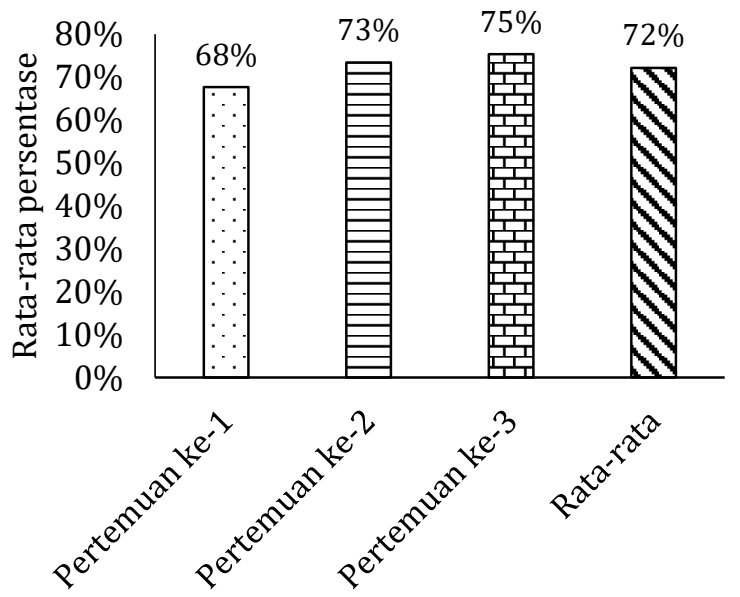

Gambar 1. Persentase rata-rata keterlaksanaan pembelajaran setiap pertemuan
Persentase rata-rata keterlaksanaan pembelajaran yang diperoleh akan dianalisis dengan kriteria ketercapaian pembelajaran sesuai pada Gambar 1. Pertemuan pertama diperoleh persentase rata-rata keterlaksanaan kegiatan pembelajaran sub materi hukum Boyle sebesar $68 \%$ kategori kurang efektif, pertemuan kedua sub materi hukum Gay Lussac sebesar $73 \%$ kategori efektif, pertemuan ketiga sub materi hukum Charles sebesar 75\% kategori efektif, dan rata-rata keterlaksanaan pembelajaran selama tiga kali pertemuan sebesar 72\% kategori efektif.

Meningkatnya setiap hasil belajar menggunakan simulasi PhET setiap pertemuan membuat peserta didik semangat dan tertarik melakukan praktikum terbukti dari meningkatnya setiap hasil rata-rata keterlaksanaan pembelajaran setiap pertemuan (Prihatiningtyas dkk, 2013:21). Terjadinya perbedaan persentase proses kegiatan pembelajaran setiap pertemuan karena tingkat perbedaan kemampuan setiap peserta didik untuk menangkap informasi yang dijelaskan guru pada saat kegiatan pembelajaran atau perbedaan gaya belajar peserta didik untuk meningkatnya daya serap saat belajar (Rochman dkk, 2018:5).

\section{Profil Penguasaan Konsep}

Profil penguasaan konsep peserta didik didapatkan bahwa penguasaan konsep peserta didik mengalami peningkatan yang dibuktikan dengan rata-rata nilai $\mathrm{N}$-Gain sebesar 0,635 kategori sedang. Hal ini karena kegiatan pembelajaran penggunaan laboratorium virtual PhET dengan tambahan model pembelajaran SAVI melatih peserta didik untuk menguasai konsep materi teori kinetik gas secara kesuluruhan tersaji pada Tabel 6 .

Tabel 6. Hasil skor pretest, posttest dan N-Gain

\begin{tabular}{cc}
\hline Variabel & Hasil \\
\hline Pretest & 39 \\
\hline Posttest & 78 \\
\hline Mean pretest-mean posttest & -39 \\
\hline Skor ideal & 100 \\
\hline Skor maksimal-mean pretest & 61 \\
\hline
\end{tabular}




\begin{tabular}{cc}
\hline Variabel & Hasil \\
\hline Jumlah pretest & 1282 \\
\hline Jumlah posttest & 2564 \\
\hline$N$-gain & 0,635 \\
\hline Interpretasi & Sedang \\
\hline
\end{tabular}

Tabel 6 menyatakan bahwa skor rata-rata tes penguasaan konsep nilai pretest yaitu 39, nilai posttest yaitu 78, dan nilai $N$-Gain 0,635. Berdasarkan interpretasi pada Tabel 6 didapatkan bahwa tes penguasaan konsep peserta didik dikategorikan mengalami peningkatan yang sedang. Peningkatan hasil kemampuan penguasaan konsep peserta didik dengan pemberian tes awal (pretest) dan tes akhir (posttest) dengan soal berupa pilihan ganda sebanyak 11 soal. Kegiatan ini dilakukan untuk mengukur penguasaan konsep peserta didik dalam materi teori kinetik gas dengan tujuan untuk menganalisis penguasaan konsep peserta didik penggunaan laboratorium virtual PhET dengan tambahan model pembelajaran SAVI. Hasil tes awal (pretest) dan tes akhir (posttest) pada menjadi bukti bahwa terdapat pengaruh penguasaan konsep penggunaan simulasi PhET (Saregar, 2016:53).

\section{Profil Ketercapaian Pembelajaran Setiap Pertemuan}

Profil ketercapaian pembelajaran rata-rata quiz tersaji pada Gambar 2, pertemuan pertama hukum Boyle, pertemuan kedua hukum GayLussac dan pertemuan ketiga hukum Charles dapat diperhatikan bahwa quiz yang dilakukan setiap pertemuan memiliki hasil persentase yang berbeda-beda. Pertemuan pertama profil keterlaksanaan penggunaan laboratorium virtual PhET dengan persentase tertinggi berada pada quiz ketiga sebesar 79\% kategori efektif, ketercapain peserta didik yang mampu menyebutkan variabel-variabel pada percobaan hukum Boyle. Persentase terendah pertemuan pertama pada quiz keenam 49\% kategori tidak efektif, dikarenakan peserta didik belum mampu membuat persamaan hukum Boyle. Pertemuan kedua materi hukum Gay Lussac persentase tertinggi pada quiz ke lima sebesar $85 \%$ kategori sangat efektif, peserta didik mampu menganalisis dan menjawab pertanyaan hubungan antara variabel tekanan dan suhu saat volume konstan materi hukum Gay-Lussac. Persentase terendah pertemuan kedua berada pada quiz pertama sebesar 59\% kategori kurang efektif, peserta didik belum mampu menjelaskan kembali materi teori kinetik gas dan hukum Boyle. Pertemuan ketiga materi hukum Charles Persentase tertinggi quiz ke tiga sebesar 94\% kategori sangat efektif, peserta didik mampu membuat tabel hasil percobaan hukum Charles. Persentase terendah pertemuan ketiga pada quiz ke enam sebesar 51\% kategori tidak efektif. Peserta didik masih kesulitan dalam membuat gradik hasil percobaaan hukum Charles. Keberhasilan peserta didik dalam menggunakan simulasi PhET dapat dilihat dari peningkatan hasil belajar peserta didik yang dilakukan selama tiga kali pertemuan yang tersaji pada Gambar 2 .

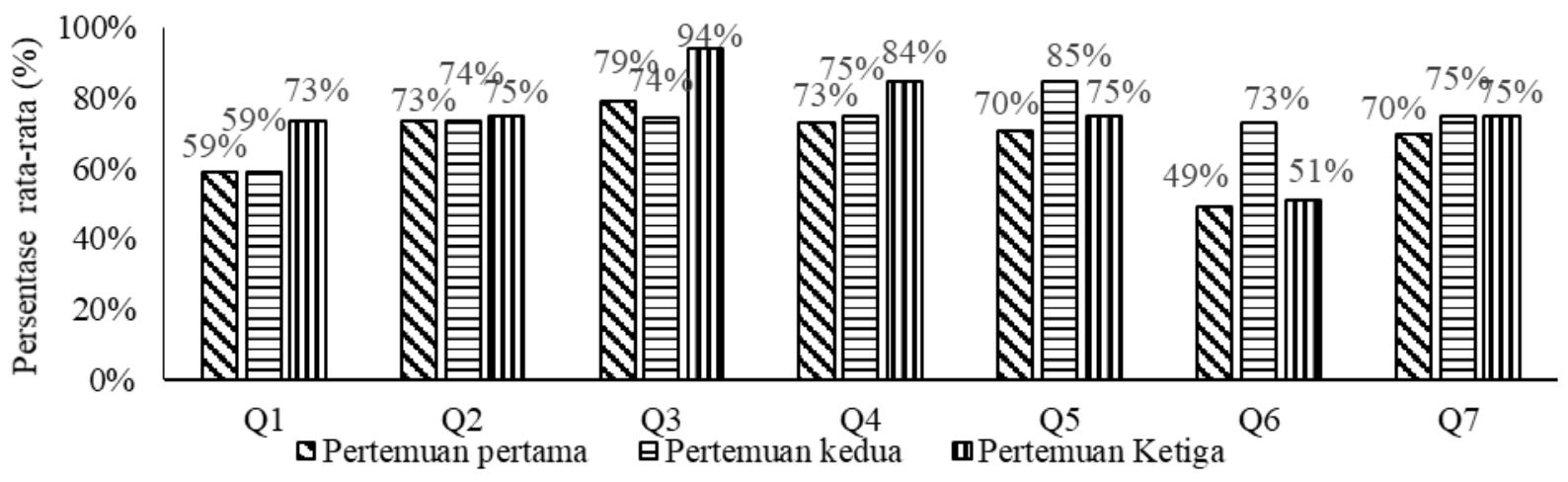

Gambar 2. Nilai rata-rata quiz setiap pertemuan 


\section{KESIMPULAN}

Berdasarkan hasil penelitian dan pembahasan yang sudah dilakukan di SMA Al-Hidayah Ciparay Kabupaten Bandung kesimpulannya bahwa (1) hasil rata-rata jawaban SAS peserta didik keterlaksanaan pembelajaran penggunaan laboratorium virtual PhET materi teori kinetik gas diperoleh dengan persentase $72 \%$ menggunakan penilaian AABTLT bahwa kegiatan pembelajaran yang dilakukan selama tiga kali pertemuan berlangsung efektif. (2) Penggunaan laboratorium virtual PhET memiliki efektifitas yang sedang untuk meningkatkan penguasaan konsep penguasaan konsep pada materi teori kinetik gas

\section{DAFTAR PUSTAKA}

Bagus Syaifulloh, rizal. (2014). Penerapan Pembelajaran Dengan Model Guided Discovery Dengan Lab Virtual PhET Untuk Meningkatkan Hasil Belajar Siswa Kelas XI Di SMAN 1 Tuban Pada Pokok Bahasan Teori Kinetik Gas. Inovasi Pendidikan Fisika, 03(02), 174-179.

Dahar. (2003). Aneka Wacana Pendidikan Ilmu Pengetahuan Alam. Bandung.

Hake, R, R. (1999). Analyzing Change/Gain Scores. AREA-D American Education Research Association's: D, Measurement and Research Methodology.

Perkins, K., Adams, W., Dubson, M., Finkelstein, N., Reid, S., \& Wieman, C. (2012). PhET : Interactive Simulations for Teaching and Learning Physics, 18(2006).

Permata, D., Lutfi, A., \& Qosyim, A. (2013). Uji Coba Pembelajaran IPA Dengan LKS Sebagai Penunjang Media Virtual PHET Untuk Melatih Keterampilan Proses Pada Materi Hukum Archimedes.

Prihatiningtyas, S., Prastowo, T., \& Jatmiko, B. (2013). Implementasi Simulasi PhET dan KIT Sederhana Untuk Mengajarkan Keterampilan Psikomotor Siswa Pada Pokok Bahasan Alat Optik, 2(1), 18-22.

Rochman, C., Cahya, E., Mahen, S., \& Nasrudin, D. (2018). Authentic Assesment Based On
Teaching and Learning Trajectory With Student Activity Sheet ( SAS ) On Basic Physic, 3(1), 1-8.

Saregar, A. (2016). Pembelajaran pengantar fisika kuantum dengan memanfaatkan media phet simulation dan LKM melalui pendekatan saintifik: Dampak pada Minat dan Penguasaan Konsep Mahasiswa. Jurnal Ilmiah Pendidikan Fisika Al-Biruni, 05(April), 53-60. https://doi.org/10.24042/jpifalbiruni.v5i1 .105

Subali, B. (2010). Penerapan Model Praktikum Problem Solving Laboratory, 6, 90-97.

Sugiyono. (2001). Metode Penelitian. Bandung: CV Alfa Beta.

Sumargo, E. (2014). Penerapan Media Laboratorium Virtual ( PhET ) Pada Materi Laju Reaksi dengan Model Pengajaran Langsung. Unesa Journal of Chemical Education, 3(1), 119-133.

Sunni, M. A., Wartono, W., \& Diantoro, M. (2014). Pengaruh Pembelajaran Problem Solving Berbantuan Phet Terhadap Penguasaan Konsep Fisika dan Kemampuan Berpikir Kritis Siswa SMA. In Prosiding Seminar Nasional Fisika (E-JOURNAL), 3, 103-107. 